\title{
ESCMID
}

\section{Abstract Book 2020}

European Congress of

Clinical Microbiology

and Infectious Diseases
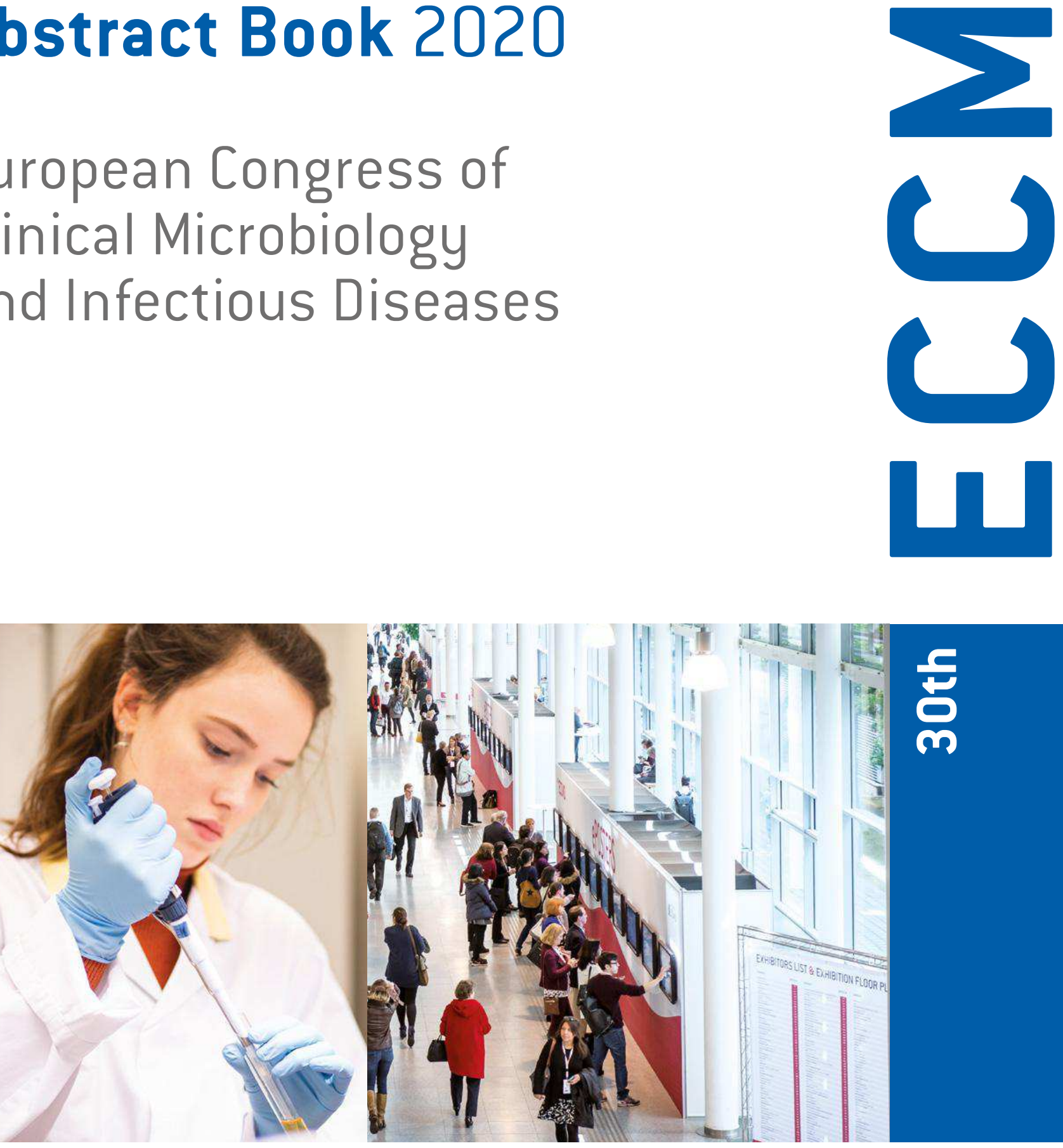

$$
\text { ह }
$$

www.eccmid.org

www.escmid.org 


\section{Table of Contents}

$4 \quad$ Welcome Address

$5 \quad$ Important Addresses

$5 \quad$ Acknowledgements

$6 \quad$ Future Congresses

$7 \quad$ Commitees

14 Abstract Programme

14 1. Viral infection \& disease

$38 \quad 2$. Bacterial infection $\&$ disease

80 3. Bacterial susceptibility \& resistance

118 4. Diagnostic bacteriology \& general microbiology

1465 New Antibacterial Agents, PK/PD \& Stewardship

170 6. Fungal infection \& disease

186 ?. Parasitic diseases \& International health

196 8. Healthcare-associated \& Nosocomial Infections, Infection Control

216 9. Experimental Microbiology, Microbial Pathogenesis \& Biofilm

$226 \quad$ 10. Immunology \& Vaccinology

238 11. Other

240 12. Late breakers

$248 \quad$ Abstracts

Disclaimer: The abstracts are presented here as they were submitted for inclusion in the proceedings of the 30th European Congress of Clinical Microbiology and Infectious Diseases (ECCMID). Outside of page layout and formatting, only the abstract titles have been proofed and edited by ESCMID. All other content entirely represents the work of the submitting author(s), and does not reflect the views of ESCMID, its staff, or its executive. ESCMID does not take responsibility for misspellings or misrepresentation of registered names, copyrights or trademarks. 
Abstract 812

Determination of pentraxin 3 levels in cerebrospinal fluid during central nervous system infections

Marta Zatta*1, Stefano DI Bella ${ }^{1}$, Barbara Bottazzi ${ }^{2}$, Francesca Rossi ${ }^{1}$, Ludovica Segat ${ }^{1}$, Pierlanfranco D'agaro ${ }^{1}$, Massimiliano Fabbiani $^{3}$, Alberto Mantovani², Roberto Luzzati ${ }^{1}$

${ }^{1}$ Trieste Hospital, Trieste, Italy, ${ }^{2}$ IRCCS Humanitas Clinical and Research Center, Milano, Italy, ${ }^{3}$ IRCCS Policlinico San Matteo, Pavia, Italy

Background: Pentraxin 3 (PTX3) is an acute phase protein; its plasmatic levels significantly raise during severe infections. Data on PTX3 levels in cerebrospinal fluid (CSF) of patients with central nervous system (CNS) infections are lacking. We aimed: a) to assess the diagnostic potential of measuring CSF PTX3 levels in patients with CNS infections; b) to establish CSF PTX3 cutoffs to distinguish between bacterial and aseptic meningoencephalitis (ROC curve).

Materials/methods: In this retrospective observational study, PTX3 levels were measured in CSF from 19 patients admitted to Trieste Hospital, Italy, with CNS infection from January 2016 to September 2018. CSF was collected by lumbar puncture performed within two hours from hospital admission. For each patient four samples of CSF were collected for obtaining these data: (1) leukocyte count, glucose and total protein levels, (2) culture and molecular amplification, (3) real-time PCR for virus (HSV 1-2, CMV, EBV, VZV, WNV, enteroviruses, TBEV and Mumps virus) and (4) PTX3 levels. The latest samples were first stored at $-80^{\circ} \mathrm{C}$ and then analysed in duplicate using a home-made sandwich ELISA. The assay has a lower limit of detection of $100 \mathrm{pg} /$ $\mathrm{ml}$, with $8-10 \%$ inter-assay variability.

Results: A diagnosis of bacterial infection and aseptic meningoencephalitis was made in 7 (37\%) and 12 (63\%) patients, respectively. Subjects with bacterial infections showed significantly higher PTX3 levels (13.5 vs $1.27 \mathrm{ng} / \mathrm{mL}$ in aseptic meningoencephalitis, $p=0.010$ ). We identified two different CSF PTX3 levels cut-offs. 1) The best cut-off to maximize Youden's J was $9.6 \mathrm{ng} / \mathrm{mL}$ with a sensitivity, specificity, positive predictive value and negative predictive value (NPV) of $71.4 \%, 91.4 \%, 83.3 \%$, $84.6 \%$, respectively; 2) The cut-off with higher NPV (100\%) was $3.6 \mathrm{ng} / \mathrm{mL}$ : a diagnosis of bacterial infections was obtained in $0 \%$ patients with CSF PTX3 levels $<3.6 \mathrm{ng} / \mathrm{mL}$ vs $58 \%$ of those with CSF PTX3 levels $\geq 3.6 \mathrm{ng} / \mathrm{mL}$ ( $p=0.017$ ).

Conclusions: CSF PTX3 levels are higher in bacterial meningitis than aseptic meningoencephalitis. A cut-off of $3.6 \mathrm{ng} / \mathrm{mL}$ of CSF PTX3 has a high NPV and can be used to exclude bacterial CNS infections.

Presenter email address: martazatta@gmail.com 